\section{CarSS SOCIAL SCIENCES}

11-14 March, 2021
Oxford - United Kingdom

\title{
On The Origins of Selected English Idioms and The Adequacy of Their Definitions in The Georgian Dictionaries (I Part)
}

\author{
Nino Dvalidze \\ Department of European Studies \\ Batumi Shota Rustaveli State University \\ 35 Ninoshvili str., Batumi, Georgia, 6010 \\ Nino.dvalidze@bsu.edu.ge
}

\section{Abstract}

The aim of this article is to fill the informative gap and to overcome those difficulties which arise in case of not having the adequate interpretation or exact definition of the English idioms in the Georgian dictionaries. This paper investigates some idiomatic expressions and observes how often they are used in the modern English publicist texts from "The Guardian", "Fortune", "The Scotsman", "The Independent" etc. whether they have preserved their original meanings or obtained some other new senses and coloring. More than this, the goal is to research if there is an adequate translation or interpretation of those English idioms in the Georgian language bilingual dictionaries. If there is not any, then the objective is how to make their adequate Georgian equivalents and, as a result to compose a new mini-dictionary of idioms. The urgent need for etymological study of idioms is also stimulated by the fact that the phraseology condensates the complex interaction of the culture and psychology of people, national self-being and their unique metaphoric mentality

The research value is dictated by its outcome, namely, it will be the research not only of those idioms which have the adequate definitions in the Georgian dictionaries, but find out some cases of not having the right definition and in result to compile the mini belingual dictionary of idioms. It can be assumed, that it will make a significant contribution to the development of lexicography in Georgia.

Keywords: adequate translation, bilingual dictionaries, etymology, idioms, mini dictionary of idioms, publicist texts. 


\section{$3^{\text {rd }}$ International Conference on Advanced Research in SOCIAL SCIENCES \\ 11-14 March, 2021 \\ Oxford - United Kingdom}

\section{Introduction}

It is said, that the cultural and educational level of the nation is measured by those mono or bilingual dictionaries, which were compiled by the lexicographers of this or that nation. They claim that long-life dedication is demanded for developing new dictionaries, but an outcome and trace is so productive and deep, that its importance is invaluable. If there weren't dictionaries, nobody would be able to learn deeply neither the native, nor foreign languages. Dictionaries play the greatest role in facilitating the intercultural dialogue. Thus, developing the new mini-dictionaries seems rather urgent affair, as the world changes rapidly and consequently does the human language. That is the reason why a good deal of researches has been still dedicating to the abovementioned issues.

The famous lexicographer Ladislav Zgusta proposes the four types of standardinfluencing dictionaries:

1. Dictionaries that aim at creating a written standard (standardcreating dictionaries): this falls into three sub-types, namely those that:

a) help to create a new standard language:

b) try to revive languages;

c) help to raise the variety of a language into a standard language of its own.

1. Dictionaries that try to make a standard more modern (modernizing dictionaries).

2. Dictionaries that try to stop any change in the standard or even to reverse linguistic change by reintroducing obsolete forms and meanings (antiquating or archaizing dictionaries).

3. Dictionaries that try to describe the existing standard, thereby clarifying it (standard descriptive dictionaries) [1].

4.

As for Robert Lew, he delivers very interesting ideas about on-line dictionaries: "Another issue that still awaits satisfactory answers is the organization of access to data in online dictionaries. Even in highly respected dictionaries, there remain basic problems of access, such as with locating multiword units, notwithstanding the upbeat tone of Meta lexicographers who often just pronounce the problem as essentially solved in the electronic medium. Other issues, related to new technologies, are the use of graphics, multimedia and 


\section{$3^{\text {rd }}$ International Conference on Advanced Research in SOCIAL SCIENCES}

11-14 March, 2021

Oxford - United Kingdom

alternative presentation modes, and these receive some attention. Finally, I play with the idea of the dictionary as an advanced query system, sitting on top of a text corpus. Using collocation dictionaries as an example, I demonstrate that the difference between a sophisticated corpus query system and a more traditional lexicographic product may soon become something of a technical subtlety" $[2,3]$.

I Would like to prove the preference to develop the bilingual mini-dictionary of idioms rather than slangs, by Rachelle Gauton's words: "Idioms and figures of speech, i.e. exocentric expressions, create special difficulties for the bilingual lexicographer as a certain amount of adaptation is necessary for the translation of these expressions. A metaphor in the SL cannot simply be translated with a corresponding metaphor in the TL. For example, the English metaphor 'Adam's apple' cannot be translated by way of a metaphor in Zulu, as such a metaphor does not exist. (The Zulu equivalent for 'Adam's apple' is the term igilo.) Mtuze (1990: 32) points out that idioms and other figurative expressions have become so fixed by usage in a particular language that it is very difficult or even impossible to render them in another language" [4].

Why did I delve into the etymology first and then tried to find their adequate definitions?! I would like to answer this question by Oktay Yağiz and Siros Izadpanah words: "phraseology condensates the complex interaction of the culture and psychology of people, national self-being and their unique metaphoric mentality" [5]. The further problem, which I had to decide, was what kind of bilingual dictionary I should compile, thematic or idioms, just arranged in the alphabetical order. For deciding this issue I acknowledged with Martin Stark's Book "Bilingual Thematic Dictionaries", which has three practical goals: "to identify the characteristic features of the bilingual thematic dictionary (BTD), to gauge its usefulness, and to make suggestions as to how it could be improved. These aims are achieved by considering the lexicographic genres (bilingual, thematic, and pedagogical) which have been combined to create this hybrid reference work, carrying out textual analyses of contemporary thematic dictionaries, and employing three pieces of user research (a questionnaire, a test, and an experiment) to reveal learners' opinions and use of BTDs" [6].

In order to carry such a great work individually and achieve the real results, one should base his work on existed corpus data, as Arleta Adamska-Salaciak mentions: "Many specialists believe that a modern dictionary worthy of the name cannot be prepared without a suitably large" electronically stored 


\section{CarsS SOCIAL SCIENCES}

11-14 March, 2021

Oxford - United Kingdom

language corpus". Corpora provide evidence for SL meanings and for the fluency of occurrence of logical items. They also help identify common syntactic patterns and recurring phraseological combinations" so that lexicographers can tap them for illustrations of various aspects of language use, which are then presented in the dictionary in the form of example sentences. On sum "it is on the basis of corpus data that representative" up-to-date word lists can be drawn up and the use of headwords illustrated" thereby ensuring that nothing of importance has been overlooked" [7].

Finally, I cannot leave without special mentioning, one of best academic online bilingual dictionary, [8] and L. R. Flavell Dictionary of idioms and their origins [9]. These resources made my research really interesting and easy to compare the chosen idioms with each other and to come to the main point of developing a new mini-dictionary of idioms, arranged in the alphabetical order.

Thus, the above mentioned authors and their researches, underling the peculiarities and difficulties of translating or giving the adequate definitions to idioms of two different cultures, stipulated my goals as the following:

The aim of this article is to fill the informative gap and to overcome those difficulties which arise in case of not having the adequate interpretation or exact definition of the English idioms in the Georgian dictionaries. One should know this while translating the idioms adequately from one language into another.

To investigate the origins of some English idioms and observe how often they are used in the modern English publicist texts from "The Guardian", "Fortune", "The Scotsman", "The Independent", etc. whether they have preserved their original meanings or acquired some new ones. If no equivalent is found, the Georgian equivalent is proposed, so that a new phraseological mini-dictionary could be compiled. It is hoped, that at least to some extent, proposing the equivalents will fill the gaps in lexicology, facilitating the intercultural dialogue.

2. Etymology of some English idioms and their adequate definitions in the Georgian dictionaries 
Delving into the etymology of words, and particularly idioms, has been aptly described by the chairman of the Harvard Department of linguistics as the "Old Curiosity Shop" of linguistic research. There are some "antiques" that can no longer be found in everyday language. Yet, there are, however, words still commonly used in English which have lost some of the shades of meaning they once had. However, these obsolete meanings are sometimes preserved in idiomatic phrases. One may often meet such idioms in the English publicist texts, so having their adequate equivalents in Georgian seems to be an urgent issue, as it may help to carry the successful intercultural dialogue.

The word beck, for instance, was used from the 14-th to the 19-th century to describe a gesture of command. In modern English, it is fossilized in the 19-th century phrase to be at someone's beck and call which means 'to be constantly at someone's service' [9]

\section{The analysis of selected idioms}

\section{1. once in a blue moon}

'very rarely, hardly ever' (Flawell 2006: 202).

Way back in the sixteenth century, to say that the moon was blue meant that an event was absurd and thus could not happen. As William Barlowe, the Bishop of Chichester, ironically put it:

Yf they saye the mone is blewe,

We muct believe that it is true.

(Rede Me and Be Nott Wrothe, c. 1526)

At exactly that period, there was a proverb in use with the same meaning but the unit held the moon to be made of green cheese: They would make men believe ... that the moon is made of green cheese (Richard Brightwell, pseudonym of John Frith, A Pistle to the Chr[iste]n Reader, 1529). Blue or green, it was absurd, and, as a consequence, could never happen. That seems to be conceptual structure underlying the earliest meaning - 'never.'

None the less the moon does, on rare occasions, appear blue when atmospheric conditions are exactly right or an event such as the eruption of Krakatoa (1883) occurs and dust particles fill the sky. A number of such instances have been recorded over recent centuries. People recognised this, and so once in a blue moon came to mean 'hardly ever,' a use which dates back to the midnineteenth century. The phrase may also have been influenced by the expression once in a moon (here referring to a phrase of the 


\section{$3^{\text {rd }}$ International Conference on Advanced Research in SOCIAL SCIENCES}

11-14 March, 2021

Oxford - United Kingdom

moon), which had existed since at least the early seventeenth century and meant 'once in a while, every now and again.'

Blue moon alone was not recorded as a figurative expression until first half of the nineteenth century when it meant 'for a long time,' as in I haven't seen you this blue moon or he won't come till a blue moon. In 1874 James Greenwood wrote in The Wilds of London:

She's agin my coming out, and takes on a bit; but it don't do to let a woman get the upper hand of you, so I sez, 'If you jaw till a blue moon in Won't alter me. You go to bed and get your bit of rest like you ought to, and I'll go out, which rainin' pitchforks I'd as life and liefer do than lay there being gnawed.

In the USA, there has been another development in the meaning. It has been the subject of extensive research. Blue moon in a technical sense is first found in the Maine Farmer's Almanac of 1937, but then through an influential misunderstanding the unit came to mean a month in which there were two full moons (which actually happens a little under every three years).

It is quite a story - 'never' to 'hardly ever' to 'for a long time' to 'rarely' to (in the USA) 'less than every three years.' Would Bishop Barlowe have believed it?

My position is not that of an anti-smoker. If you want to smoke in my house, fine. Or over lunch.

In my even join you once in a blue moon.

"The Spectator", 30 June 2001.

In Georgian bilingual dictionaries, the expression once in a blue moon is also defined as

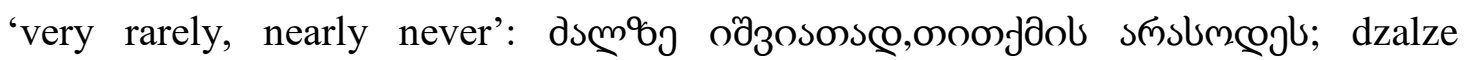
ishviatad,titkmis arasodes (CEGOLD).

\section{2. moot point}

'an issue which is open to various interpretations or viewpoints, to which no satisfactory answer is found' (Flawell 2006: 203)

The word moot means 'meeting'. It ultimately derives from a prehistoric Germanic word motam

'meeting.' In Anglo-Saxon and early medieval England, a moot signified in particular a local 'judicial assembly'. The term was also used to describe the arguments, discussions and litigation that took place at such meetings. During the sixteenth century, law students at the Inns of Court would argue hypothetical cases for practice. These debates, too, were known as moots. The phrase moot case/point arose around this time to 


\section{CarsS SOCIAL SCIENCES}

11-14 March, 2021

Oxford - United Kingdom

describe a 'law-case proposed for discussion'. By the eighteenth century, the expression was no longer confined to debatable points of law but was being more generally applied to instances where there were various interpretations, but no definitive answers.

The contemporary sense of the word moot in American English is 'academic' and 'irrelevant,' as in the example from the "Wisconsin State Journal" of 3 April 2005: it is clear that Wisconsin is one of the most highly taxed states, whether third of fifth is a moot point while considering that there are 50 states. Some examples of modern use are given below:

Is Mr Davies saying that Asian teenagers are the target audience for the bilge that Dyke has been putting on our screens? Does he believe that Asian teenagers would rather watch Porn Star than the proceedings of the party conferences, which are now to be axed from the principal channels? It is a moot point.

"The Daily Telegraph", 14 March 2002.

There has never been a pop record quite like Bob Dylan's 'Like A Rolling Stone.' For one thing, at close on six minutes, it was twice as long as the average single but it also, at a stroke, expanded the vocabulary of pop music.

Whether it's worth a whole book, however, is a moot point, although if anyone can carry off such a conceit it's Greil Marcus, the high priest of rock journalism'.

“Birmingham Post", 30 April 2005.

In the bilingual dictionary, two different definitions of the phrase a moot point are presented: 1. 'an issue which is open to various interpretations or viewpoints, to which no satisfactory answer is found' 2. 'the issue which lost the actuality' (American version):

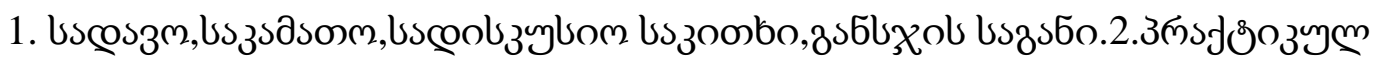

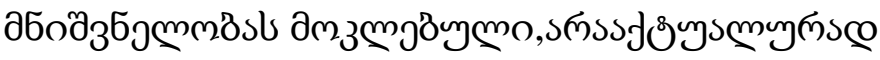

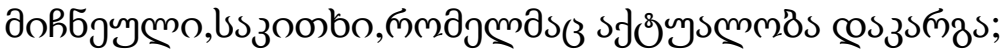

1. sadavo, sakamato, sadiskusio sakitkhi.gansjis sagani, 2. praqtikul mnishvnelobas moklebuli, araatualurad michneuli, sakitkhi, romelmac aqtualoba dakarga (CEGOLD).

\section{3 to make a mountain out of a molehill}

'to make a small problem or grievance seem much greater than it really is' (Flawell 2006: 204) 


\section{$3^{\text {rd }}$ International Conference on Advanced Research in SOCIAL SCIENCES}

11-14 March, 2021

Oxford - United Kingdom

The ancients had a variety of phrases to encapsulate the idea of blowing up a trifling matter out of all proportion. One such was the Latin to make a triumphal arch out of a sewer, a favourite of Cicero's, and another was the Greek to make an elephant out a fly, an expression which has passed into French as faire d'une mouche un éléphant. The English phrase, with its pleasing alliteration, dates from the sixteenth century, with an early mention in Thomas Becon's Catechism (1560). The use of the phrase is exemplified below:

All parents get bad tempered sometimes. I tell you that you're making a mountain out of a molehill'. Ann Widdecombe, The Clematis Tree (2000).

Junior Foreign Minister Conor Lenihan shamed himself and Ireland with his racist outburst yesterday ... Some people might think this is making a mountain out of a molehill - but they are people not at the receiving end.

"Daily Mirror", 19 May 2005.

The expression to make a mountain out of a molehill has an adequate equivalent in Georgian, which means to exaggerate things so that the fly may seem to you an elephant:

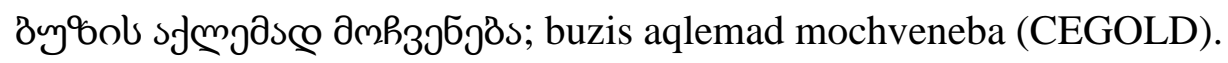

\section{4 to make one's mouth water}

'to cause one to anticipate something with relish; to tempt, tantalise' (Flawell 2006: 206)

These craftie foxes (...) espying their enemies a farre of, beganne to swalowe theyr spettle as their mouthes watered for greediness of theyr pray. So wrote Richard Eden in Decades of the Newe Worlde (1555), a translation of Spanish historian Peter Martyr's work. The craftie foxes in the passage are, in fact, slobbering cannibals, their salivary glands running in anticipation of a human feast. By the mid-seventeenth century, mouths were figuratively watering for things other than food: The Mountains of Gold did it for Cortez, the conquistador or Mexico (North's Plutarch: Additional Lives, 1657), while, a century or so later, Tristram Shandy's uncle Toby salivated for a puff on his beloved pipe (Laurence Sterne, Tristram Shandy, 1759-67). The following excerpts illustrate the use of the expression in question in modern texts:

With smooth lines, tactile fabrics and colours to make your mouth water, European designers are in vogue at contemporary furnishing fairs worldwide.

"Daily Record", 9 July 2002.

And, by God, there she was - a drop-dead gorgeous screen goddess in a 1940s swimsuit, strerched out in the California sun. my jaw dropped. Her home movies had a cast that have made MGM's corporate mouth water.

“The Daily Telegraph", 12 October 2002. 
The idiom to make one's mouth water has also an adequate equivalent in Georgian, which literally translated means to tempt somebody to eat or have something, o arise in somebody a very strong wish or appetite to have something: Зоळ̆

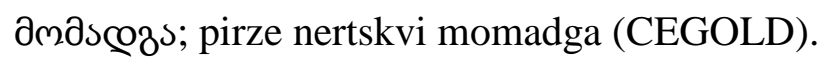

\section{5 mug's game}

'a foolish activity that gives no pleasure or profit' (Flawell 2006: 207)

The word mug has been a slang term for a stupid or inadequate person since the midnineteenth century. The term was particularly applied to one who was easily duped: The method of plucking the mug varies according to circumstances ("The Sporting Times", 3 August 1889). The phrase mug's game meaning 'a foolish pursuit or activity's' has been in use since the early twentieth century. The expression occurs in the contemporary press, as attested below:

If inflation is destroying the value of money, then saving is a mug's game and borrowing is sensible.

“The Daily Mail on Sunday”, 31 August 2003.

Economic forecasting is, most of the time, a mug's game. Economists are alleged to have forecast ten of the past three recessions. "The Scotsman", 3 November 2003.

In English-Georgian lexicography, a mug's game is interpreted as something that is idle and useless. It sounds in Georgian like this: oy usargeblo (CEGOLD).

\section{6 mum's the word}

'don't say anything about it, keep the secret' (Flawell 2006: 207)

The word mum has meant 'silence' through an inability or unwillingness to speak since the fourteenth century, the word being imitative of the sound made when the lips are firmly pressed together. The idiom itself, a pledge or command to secrecy, dates from the 1660s. An earlier form, mum is counsel, goes back to the mid-sixteenth 


\section{$3^{\text {rd }}$ International Conference on Advanced Research in SOCIAL SCIENCES \\ 11-14 March, 2021 \\ Oxford - United Kingdom}

century. Another variant to keep mum dates only from the first half of the nineteenth century.

Recently, the expression mum's the word has become a well-worn and therefore clichéd headline used by journalists reporting on anything at all to do with the family: Mum's the word: After a rocky patch Charlotte Church and her mum are close again ("Daily Mail", 27 May 2004).

The pun has worn rather thin, as can be observed in the examples below:

Can you keep a secret, ladies and gentlemen? I think Jeremy may have had a few. Ssshhh.

Mum's the word.

“The Daily Telegraph”, 16 November 2003

WHO WILL OCCUPY MONROE STREET’S ‘GROGERY PALACE’?

Those closest to the negotiations between potential grocers seeking to lease ground-floor retail space at the Monroe Commons multi-use development and Monroe Neighbors LLC are keeping mum.

“Capital Times", 11 May 2005

The Georgian equivalent of the idiom mum's the word is 'keep silent, do not say a

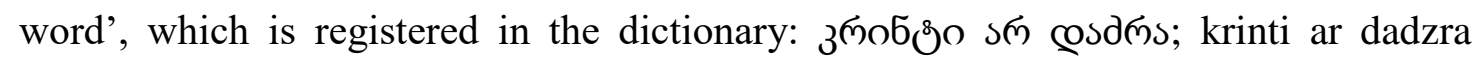
(CEGOLD).

\section{7 mumbo jumbo}

'nonsense, something that has no meaning (said of jargon or a system of belief' (Flawell 2006: 207)

In July 1734, Francis Moore left England for West Africa as a writer in the service of the Royal African Company, a trading company that dealt in commodities such as gold, beeswax, ivory and slaves. In his Travels Into the Inland Parts of Africa (1738), he tells of Mumbo Jumbo, a spirit invented by the men of the villages along the Gambia river to keep their womenfolk in order:

The women are kept in the greatest subjection; and the men, to render their power as complete as possible, influence their wives to give them an unlimited obedience, by all the force of fear and terror. For this purpose the Mundingoes have a kind of image eight or nine feet high, made of the bark of trees, dressed in a long coat, and crowned with a wisp of straw. This is called a Mumbo Jumbo; and whenever the men have any dispute with the women, this is sent for to determine the contest, which is almost always 
done in favour of the men. One, who is in the secret, conceals himself under the coat, and bringing in the image, is the oracle on these occasions.

In the on-line dictionary, mumbo jumbo is also interpreted by as the 'senseless,

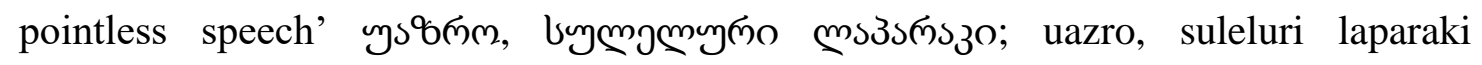
(CEGOLD).

\section{8 to scream /shout/cry blue murder}

'to shout aloud in alarm or distress' (Flawell 2006: 209)

The French oath morbleu, a euphemism for mort dieu, 'God's death', has been in English as a comic exclamation since the seventeenth century. It is a contraction of Middle French mort bleu, which appropriately translates not as 'blue death' but as 'blue murder', since various contemporary English words meaning 'slaughter, murder' share a common origin and meaning with the French mort. The expression blue murder is listed in John Camden Hotten's Dictionary of Modern Slang, Cant, and Vulgar Words (1859) with the definition a 'desperate or alarming cry', showing that it had been current enough to merit inclusion. It is now used as an intensifier, mainly with scream and shout and cry, to emphasize the ferocity of the shriek as exemplified below:

Sarah comes across remarkably unsympathetically, hogging the family's precious resources, screaming blue murder and - quite probably - duping and manipulating most if not all of those who cared for her into believing she wasn't eating. The Daily Telegrah", 2 March 2003.

The air-raid siren screams blue murder as I run across a deserted Westminster trying to escape a nuclear attack.

"The Guardian”, 14 July 2004.

In the on-line dictionary, the expression screaming blue murder is defined as the

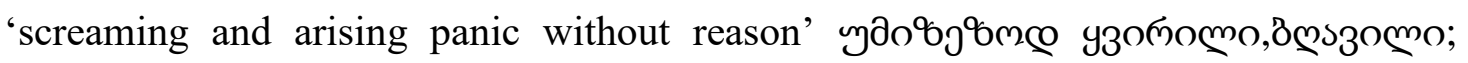
umizezod kvirili, bghavili.

(CEGOLD).

\section{9 as keen as mustard}

'enthusiastic over cause or undertaking' (Flawell 2006: 209).

Since the introduction of the congestion charge, Ken Livingstone's Transport for London (TFL) have been keen as mustard to promote the idea of cycling in the capital. "The Big Issue", January 2004. 


\section{$3^{\text {rd }}$ International Conference on Advanced Research in SOCIAL SCIENCES}

11-14 March, 2021

Oxford - United Kingdom

Glamorgan believe the signing of India Test captain Sourav Ganguly will spark a dramatic turnaround in their Frizzell County Championship fortunes.

Sourav's as keen as mustard, and can't wait to get started', revealed Derrick.

"Western Mail", 26 May 2005.

The idiom as keen as mustard is defined in the bilingual dictionary adequately as 'full of enthusiasm and very interested in something', as well as 'very bright and sharp-

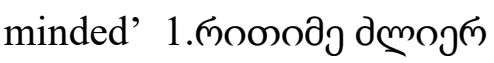

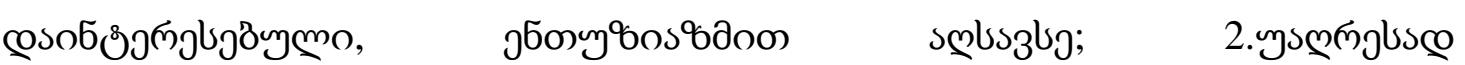

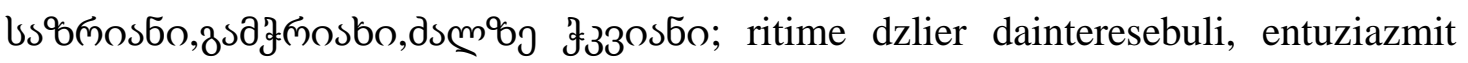
aghsavse; uaghresad sazriani, gamchriakhi,dzalze chkviani) (CEGOLD).

\subsection{0 to cut the mustard}

'to come up to standard' (Flawell 2006: 210)

The word mustard, a name of a condiment noted for its zest and piquancy, has been in figurative use since the seventeenth century when as keen as mustard was coined to describe a person full of enthusiasm for a cause or undertaking. Around the turn of the twentieth century, the word mustard was a slang term in American English denoting 'the best anything'. It was the ingredient that made all the difference: I'm not headlined in the bills, but I'm the mustard in the salad dressing just the same (O'Henry, The Phonograph and the Graft, in: Cabbages and Kings, 1903). This is probably the origin of the unit to cut the mustard, meaning 'to come up to expectations'. It is first recorded in 1902, also in O’Henry (Cupid à la Carte): By nature and doctrines I am addicted to the habit of discovering choice places wherein to feed. So I looked around and found a proposition that exactly cut the mustard. I found a restaurant tent just opened up by an outfit that had drifted in on the tail of the boom.

There are, however, other theories as to the idiom's etymology. One of these alludes to the common practice of adding vinegar to mustard to "cut" its sharp flavor; another says it is a corruption of the synonymous military idiom to pass muster, meaning 'to pass inspection', 'to make the grade'. There is now a tendency to use the expression in negative contexts, an in the examples below:

"In terms of adding value to your home, a separate dining room no longer cuts the mustard.

'The kitchen has taken over as the top room in the house", says Graham Harris.

“Good Housekeeping”, April 2000. 
 SOCIAL SCIENCES}

11-14 March, 2021

Oxford - United Kingdom

I'm also learning to be a computer expert, because a few pictures cut from a magazine and some nice handwriting no longer cut the mustard when it comes to school projects. Now it's got to be downloaded images from the internet with 60 different typefaces. “Good Housekeeping”, February 2002.

In the consulted bilingual dictionary, to cut the mustard is interpreted as 'totally

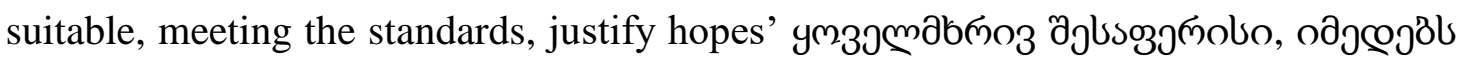

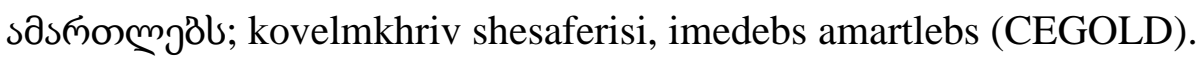

\subsection{1 to pass muster}

'to come up to standard, to bear scrutiny' (Flawell 2006: 210)

The word muster derives from the Latin verb monstrare, 'to show' and, from the early fifteenth century onwards, was used to describe the assembling of troops for inspection. The phrase to pass muster (originally to pass the musters) dates from the sixteenth century and meant 'to undergo a successful military inspection'. There is an instance from the same period where the expression is used figuratively but this idiomatic sense seems not to have become widespread till the first half of the eighteenth century. The idiom occurs in press texts, as exemplified below:

Jasper Jackson ... leads an enviable life, spending most days at a desk in his attic flat and buying his dinner from a bizarre pair of shopkeepers called Roy $\mathrm{Sr}$ and Roy Jr (who are so aghast at his lifestyle that they put up the prices daily to see if he notices). Too uptight to pass muster as a lovable rogue, he extols the virtues of the liberated life without quite enough conviction'.

“The Independent”, 6 July 2003.

Nearly 70 percent of the Erie Parking Authority's older, mechanical parking meters failed state certification testing, and must be replaced. Raymond Massing, the authority' executive director, said timing devices inside 750 of the 1,085 mechanical meters tested by inspectors from the state's Department of Agriculture couldn't pass muster.

“Erie Times-News", 11 May 2005.

In the on-line source, the idiom to pass muster is defined as the 'passing the checking

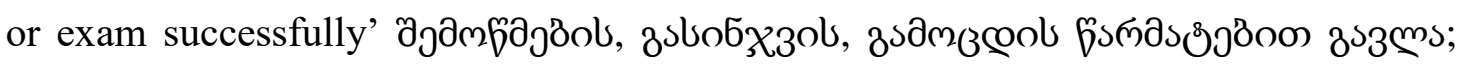
shemotsmebis, gasinjvis, gamocdis tsarmatebit gavla (CEGOLD). 


\section{$3^{\text {rd }}$ International Conference on Advanced Research in SOCIAL SCIENCES \\ 11-14 March, 2021 \\ Oxford - United Kingdom \\ 2.12 dressed as lamb}

'an older woman dressed in clothes more suited to a younger one' (Flawell 2006: 211)

The idiom could be motivated by comparing old meat with young meat, or a sheep with a lamb. The word mutton has long been derogatory when applied to woman. From the early sixteenth century onwards, it was a slang term for a 'prostitute', and the phrase to hawk one's mutton, meaning 'to solicit', is surprisingly modern, dating back only as far as the first half of the twentieth century. It has the sense of offering one's flesh for profit.

However, the word mutton was also sometimes used to denote 'a sheep', a sense that was obsolete by the nineteenth century, except for humorous effect, and this jocular tone would fit well with the light-hearted early-nineteenth century idiom mutton dressed as lamb. However, there is also the matter of to dress. Meat has been dressed, that is 'prepared for cooking', since at least the early fourteenth century. The expression thus suggests preparing an older cut of meat to look and taste like young lamb. Today, dressed in this phrase carries the idea of 'wearing', the phrase referring to older women inappropriately decked out in the fashions and clothing of the young.

Most of us find it tougher to steer a line between wanting to grow old at least a little disgracefully and the very female fear of being mutton dressed as lamb.

“The Times", 16 October 2001.

I recently chucked out clothes that I wore in younger days, telling myself: 'I'm never going to wear that rara skirt again!

Luckily, my husband, Grand, would never let me leave the house looking like mutton dressed as lamb.

“Daily Mail”, 20 November 2001.

If you're 18 and on the pull this is your shop. Pelmet skirts, noisy prints, Lycra everything, ubiquitous midriffs. No quality but bags of fun. Anyone over 24 will and up looking like mutton dressed as lamb, and if you're big-busted or bigbottomed, don't bother.

“The Times”, 28 February 2002.

In the English-Georgian dictionary, the idiomatic expression mutton dressed as lamb is defined in a similar way to the above mentioned phrase: 'older woman dressed in

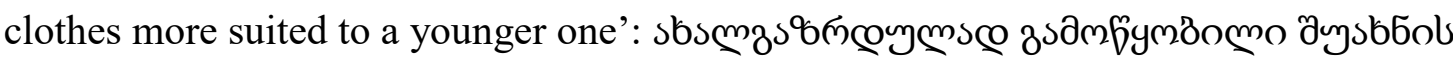
sб slsзzм3s6o jsmo; akhalgazrdulad gamotskobili shuakhnis an asakovani qali (CEGOLD). 


\section{$3^{\text {rd }}$ International Conference on Advanced Research in SOCIAL SCIENCES \\ 11-14 March, 2021 \\ Oxford - United Kingdom \\ 2.13 mutual admiration society}

'a pair or group given to praising and promoting each other's interests' (Flawell 2006: 211)

The expression mutual admiration society is first recorded in the New York literary magazine "The Knickerbocker" in 1845. A little later it is found in the writings of the American philosopher, essayist and poet Henry David Thoreau (1817-62), in a journal entry dated 27 February 1851:

The lecturer is wont to describe the Nineteenth Century, the American [of] the last generation, in an off-hand and triumphant strain, wafting him to paradise, spreading his fame by steam and telegraph, recounting the number of wooden stopples he has whittled. But who does not perceive that this is not a sincere or pertinent account of any man's or nation's life? It is the hiphip-hurrah and mutual-admiration-society style.

Within seven years the phrase was taken up by American poet and jurist Oliver Wendell Holmes and from this period onwards was current on both sides of the Atlantic, often as a satirical barb to describe any group where the members are overly effusive and self-promoting in their reciprocal esteem.

Below there are some examples of the use of the phrase observed in modern press texts, the first one about Margaret Thatcher and Ronald Reagan:

We all know how much Mrs Thatcher admired Reagan and that, from the latter's arrival in office in 1981, they formed a powerful mutual admiration society. "The Guardian", 8 June 2004.

Another is about Helen Mirren who has taken Scarlett Johansson under her wing. The two award-winning actresses are serving on the Venice Film festival jury - and their blossoming friendship is obvious for all to see, which is described in the passage below:

They seem to have become a mutual admiration society - and it's based on respect for each other's work', marc Mueller, the festival's director, told me when I remarked on how the two women were making each other laugh.

“Daily Mail”, 3 September 2004.

The last excerpt mentions two politicians, mainly two presidents: George W. Bush and Vladimir Putin: 


\section{$3^{\text {rd }}$ International Conference on Advanced Research in SOCIAL SCIENCES \\ 11-14 March, 2021 \\ Oxford - United Kingdom}

When President Bush and Russian President Vladimir Putin came out to meet the press yesterday, it was not to engage in the sparring match some had anticipated. It was more of a celebration of mutual admiration'.

"Washington Post", 25 February 2005.

In the on-line lexicographic source, the idiom mutual admiration society is interpreted as: 'the group of people who have the common interests and exaggerate and praise too

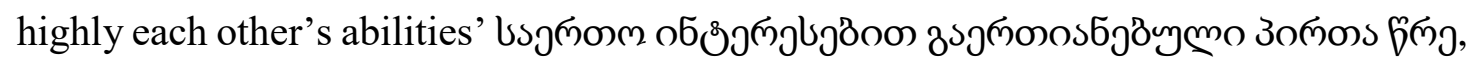

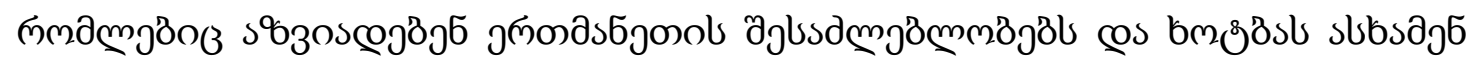

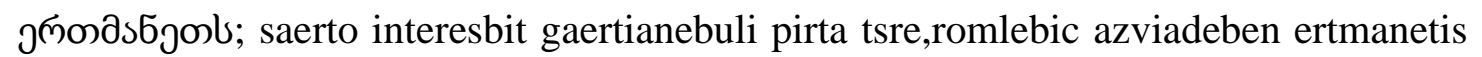
shesadzleblobebs da xotbas asxamen ertmanets (CEGOLD).

\section{Results and Discussions}

The appropriate definitions of some English idioms were found in the Georgian dictionaries in order to fill the informative gap between cultures.

The origins of some English idioms were investigated and observed how often they were used in the modern English publicist texts from "The Guardian", "Fortune", "The Scotsman", "The Independent", to observe whether they have preserved their original meanings or acquired some new ones

The importance of compiling the new bilingual dictionaries was underlined generally.

Some cases of not having the exact definition were found out and in result I am going to develop the mini bilingual dictionary of idioms, arranged in the alphabetical order.

\section{Conclusions}

1. The idea that some old idioms can no longer be found in everyday language did not appear true, since some antique words and phrases still are commonly used in the English language, especially we may meet them in everyday conversations and press articles.

2. Some of the idioms have lost some of the shades of meaning they once had, but their obsolete meanings are preserved in idiomatic phrases, which proves 


\section{$3^{\text {rd }}$ International Conference on Advanced Research in

that phraseological stock is a reservoir of archaisms. That's why there was an urgent need of investigating the etymology of selected idioms.

3. Almost all the analyzed English idioms have adequate translations and interpretations in the Georgian dictionaries. If continued, such research studies as the present one will contribute to developing a new English-Georgian dictionary of idioms.

4. The research value is dictated by its outcome, namely, it will be the research not only of those idioms which have the adequate definitions in the Georgian dictionaries, but find out some cases of not having the right definition and in result to develop the mini bilingual dictionary of idioms. It can be assumed, that it will make a significant contribution to the development of lexicography in Georgia.

\section{References}

[1] Zgusta, L.; Creamer, T. B. I. (Ed.) (2006). Lexicography Then and Now. Tubingen, Munchen: Max Niemeyer Velarg, $404 . \quad$ doi: http://doi.org/10.1515/9783110924459

[2] Lew, R. (2011). Online Dictionaries of English. The Internet, Digital Initiatives and Lexicography. Continuum, 230-250. doi: http://doi.org/10.5040/9781474211833.ch-011 


\section{$3^{\text {rd }}$ International Conference on Advanced Research in} SOCIAL SCIENCES

11-14 March, 2021

Oxford - United Kingdom

[3] Müller-Spitzer, C. (Ed.) (2014). Using online Dictionaries. Berlin: De Gruyter, 388. doi:

http://doi.org/10.1515/9783110341287

[4] Gauton, R. (2008). Bilingual Dictionaries, the Lexicographer and the Translator. Lexikos, 18, 106-118. doi: http://doi.org/ 10.5788/18-0-479

[5] Yağiz, O., Izadpanah, S. (2013). Language, Culture, Idioms, and Their Relationship with the Foreign Language. Journal of Language Teaching and Research, 4 (5). doi: https//doi.org/10.4304/jltr.4.5.953-957

[6] Stark, M. (2011). Bilingual Thematic Dictionaries. Berlin: Walter de Gruyter, 486. doi:

http://doi.org/10.1515/9783110258899

[7] Adamska-Salaciak, A. (2013). Issues in compiling bilingual dictionaries. The Bloomsbury

Companion to Lexicography. London, 213-231. doi: http://doi.org/10.5040/9781472541871.ch-011

[8] Comprehensive English-Georgian On-Line Dictionary (2009). Margaliti Limited and TSU. A joint project. Ivane Javakhishvili Tbilisi State University. Available at: http://dictionary.ge/en/

[9] Flavell, Linda and Roger (2006). Dictionary of idioms and their origins. London: Kyle Cathie, 216.

[10] Green, J. (1995). Slang down the Ages. London: Kyle Cathie.

[11] Gvarjaladze, Thamar and Isidore (1975). English-Georgian Dictionary. Tbilisi: Georgia. 